\title{
Optical bench performance of a novel trifocal intraocular lens compared with a multifocal intraocular lens
}

This article was published in the following Dove Press journal:

Clinical Ophthalmology

2 June 2016

Number of times this article has been viewed

\author{
Shinwook Lee \\ Myoung Choi \\ Zaiwei Xu \\ Zeyu Zhao \\ Elsinore Alexander \\ Yueai Liu \\ Alcon Research, Ltd., Fort Worth, \\ TX, USA
}

Correspondence: Shinwook Lee Alcon Research, Ltd.,

620I South Freeway, Fort Worth,

TX 76I34-200I, USA

Tel +I 8I76I5 5075

Email shinwook.lee@alcon.com
Purpose: The purpose of this study is to compare the optical characteristics of the novel PanOptix presbyopia-correcting trifocal intraocular lens (IOL) and the multifocal ReSTOR +3.0 D IOL, through in vitro bench investigations.

Methods: The optical characteristics of AcrySof ${ }^{\mathbb{B}}$ IQ PanOptix ${ }^{\mathrm{TM}}$ (PanOptix) and AcrySof ${ }^{\mathbb{B}}$ IQ ReSTOR +3.0 D (ReSTOR +3.0 D) IOLs were evaluated by through-focus Badal images, simulated headlight images, and modulation transfer function (MTF) measurements which determine resolution, photic phenomena, and image quality. Through-focus Badal images of an Early Treatment of Diabetic Retinopathy Study chart were recorded at both photopic and mesopic pupil sizes. Simulated headlight images were taken on an MTF bench with a 50- $\mu \mathrm{m}$ pinhole target and a $5.0 \mathrm{~mm}$ pupil at the distance focus of the IOL. MTF curves were measured with a $3.0 \mathrm{~mm}$ pupil, and spatial frequencies equivalent to 20/40 and 20/20 visual acuities were recorded to illustrate the through-focus MTF curves. Far-, intermediate-, and near-focus MTF values were obtained.

Results: Bench Badal image testing and MTF measurements showed that PanOptix has a near focus at a distance of $42 \mathrm{~cm}$ and an additional intermediate focus at a distance of about $60 \mathrm{~cm}$. The near focus for ReSTOR +3.0 D is at $45 \mathrm{~cm}$. PanOptix and ReSTOR +3.0 D have comparable photopic distances and near MTF values. Additionally, PanOptix provided a substantial continuous range of vision from distance to intermediate and to near compared with ReSTOR +3.0 D. The halo propensity for PanOptix was slightly higher than that for ReSTOR +3.0 D.

Conclusion: Laboratory-based in vitro simulations showed that PanOptix trifocal IOL has comparable resolution and image quality performance in distance and near foci compared with ReSTOR +3.0 D IOL. PanOptix showed better resolution and image quality performance at the intermediate focus than ReSTOR +3.0 D IOL.

Keywords: multifocal, trifocal, modulation transfer function, Badal image, visual acuity, headlight images

\section{Introduction}

Cataract surgery techniques and technologies have improved the surgery from a procedure that could prevent blindness to a procedure that maximizes visual performance. ${ }^{1-3}$ The overwhelming majority of intraocular lens (IOL) implants after phacoemulsification surgery and cataract removal are monofocal IOLs, which have been specifically designed to improve the distance of optical resolution and have very few complications associated with the material or the technology. ${ }^{1-3}$ However, most of the patients will still require spectacles for near and intermediate tasks, including computer work. The ongoing need for spectacle use after surgery has, in turn, decreased 
the overall patient satisfaction and perceived quality of life, ${ }^{1-4}$ especially in younger patients who typically have more demands for spectacle-free vision for their lifestyle, reading, and computer work. ${ }^{5}$

The advent of multifocal IOLs introduced an effective solution for spectacle independence after cataract surgery and added to the surgical options for the correction of presbyopia. ${ }^{1,6-10}$ Compared with monofocal IOL capabilities, multifocal IOLs have been shown to increase the depth of vision, maintain distance vision, and improve near vision. . $3,6,7,11$ The first-generation multifocal IOLs are apodized diffractive lenses that send energy to two focal points in small pupils and only to distance points in larger pupils, using the zero and first diffraction orders for distance and near foci, respectively. Because of their design, multifocal IOLs are generally ineffective in improving intermediate vision tasks..$^{6,9,10}$ Also, these lenses have been associated with halos, reduced contrast sensitivity, and increased dysphotopsia, which can lead to ongoing patient dissatisfaction. ${ }^{1,7,12,13}$ Whether the potential visual complications from multifocal lenses outweigh the gain of additional spectacle independence depends on patient preference and adaptability.

Trifocality in IOL designs has been found to provide good near, intermediate, and distance visual performances and increase spectacle independence. ${ }^{14}$ AcrySof $^{\circledR}$ IQ PanOptix ${ }^{\mathrm{TM}}$ Presbyopia Correcting IOLs (PanOptix; Alcon Research, Fort Worth, TX, USA) are trifocal IOLs that have been CE Mark-approved in Europe. The lens is made up of the same hydrophobic and ultraviolet- and blue light-filtering acrylate/ methacrylate copolymer material used in the AcrySof family of lenses (Alcon Research). The lens design is intended to improve the intermediate vision tasks and increase patient satisfaction, with a third focal point at an optimal intermediate distance of $60 \mathrm{~cm}$. PanOptix is a nonapodized diffractive trifocal IOL that distributes light energy to three focal points in both small and large pupil conditions. It uses zeroth, second, and third nonsequential diffraction orders for distance, intermediate, and near foci, respectively, and the energy at the first diffractive order is redistributed to optimize the performance at three other focal points. This novel diffractive structure produces high light utilization, transmitting $88 \%$ of light at the simulated $3.0 \mathrm{~mm}$ pupil size to the retina. ${ }^{15}$ The light is split into two with one half allocated to the distance focus and the other half split between the near and intermediate focus. PanOptix is also designed with an intermediary $4.5 \mathrm{~mm}$ diffractive zone, making its performance less dependent on pupil size.
Optical bench evaluation is a well-known method to determine the optical quality of IOLs. ${ }^{911,16,17}$ This study compared the results of various bench simulations of visual performance: through-focus modulation transfer function (MTF), through-focus Badal image testing, and headlight image testing for PanOptix and ReSTOR +3.0 D. ReSTOR +3.0 D was selected as the comparator lens because it is a multifocal IOL with established good distance and near visual acuity (VA). ${ }^{18}$ This study chose those particular bench tests on the basis of their specificity: through-focus Badal images to test optical resolution, headlight images to assess the photic phenomena associated with IOLs, and through-focus MTF curves to assess image quality by quantifying the contrast passing through a system at a given spatial frequency. $5,6,9$

\section{Methods}

\section{Intraocular lenses}

ReSTOR +3.0 D IOLs (model SN6AD1; Alcon Research) and PanOptix IOLs that are used in this study had a 21.0 $\mathrm{D}$ base power. ReSTOR $+3.0 \mathrm{D}$ is an apodized diffractive multifocal IOL, whereas PanOptix is a nonapodized diffractive trifocal IOL.

ReSTOR +3.0 D and PanOptix have aspherical designs and aspheric corrections for a corneal spherical aberration of $-0.1 \mu \mathrm{m} .{ }^{19}$ Table 1 lists the optical specifications of ReSTOR +3.0 D and PanOptix.

ReSTOR +3.0 D has active diffraction orders of the zeroth and first magnitude, and PanOptix IOL has active diffraction orders of the zeroth, second, and third magnitude. The optical technology of PanOptix uses nonsequential diffractive orders to create near $(42 \mathrm{~cm})$, distance, and intermediate $(60 \mathrm{~cm})$ foci. ${ }^{20}$ In PanOptix, energy at the first diffractive order is redistributed to optimize the performance at the other focal points. ${ }^{20}$

Table I Characteristics of ReSTOR +3.0 D and PanOptix IOLs

\begin{tabular}{lll}
\hline & PanOptix & ReSTOR +3.0 D \\
\hline Technology & Trifocal & Multifocal \\
Diffractive zone & $4.5 \mathrm{~mm}$ & $3.6 \mathrm{~mm}$ \\
Central zone & Diffractive & Diffractive \\
Optic type & Nonapodized & Apodized \\
Near add powers & $+3.25 \mathrm{D}$ & $+3.00 \mathrm{D}$ \\
Intermediate & $+2.17 \mathrm{D}$ & None \\
add powers & & \\
Active orders & Zeroth, second, & Zeroth and first \\
& and third & \\
Asphericity & $-0.1 \mu \mathrm{m}$ & $-0.1 \mu \mathrm{m}$ \\
Lens color & Yellow & Yellow \\
\hline
\end{tabular}




\section{Experimental design \\ Badal imaging}

A custom model eye was assembled as a Badal optometer, as previously described by Carson et al. ${ }^{5}$ The model eye used for testing both the study lenses was modified with $0.1 \mu \mathrm{m}$ spherical aberration according to the design of the lenses. A bench simulation of visual performance using through-focus Badal image testing of an Early Treatment of Diabetic Retinopathy Study chart from $-1.0 \mathrm{D}$ to $+3.0 \mathrm{D}$ at $0.25 \mathrm{D}$ increments was performed, and images simulating viewing distances from infinity to $40 \mathrm{~cm}$ were evaluated. An additional image was also taken at the best near focus of each lens in order to account for the differences in near add power. Badal images taken with the letter chart target placed at the simulated depth of foci of infinity, 80, 60, $40 \mathrm{~cm}$, and best near focus were depicted to demonstrate the difference between the two lens models.

The IOLs were positioned within a model eye containing deionized water and a convex plano model cornea lens with a matching spherical aberration, as described previously; the IOL was held on a paddle that contained a $3.0 \mathrm{~mm}$ pupil. The target was a chrome-on-glass, $25 \mathrm{~mm}$ diameter Early Treatment of Diabetic Retinopathy Study VA chart that depicted nine rows, with the smallest row corresponding to a VA of 20/12. VA difference of no more than two letters is considered equivalent at a given focus distance (less than one-half of the clinically relevant value of 0.1 logarithm of the minimum angle of resolution).

\section{Simulated headlight imaging}

Photic phenomena of the two IOLs in the form of halo propensity assessment were measured using the Optikos MTF System (Optikos Corp., Wakefield, MA, USA) with OpTest $^{\mathrm{TM}}$ software (version 5.2.2; Optikos Corp.) in a pseudophakic eye model with a spherical aberration matching International Organization of Standardizations model eye as previously described by Carson et al. ${ }^{5}$ An illuminated pinhole with a $50 \mu \mathrm{m}$ aperture was used to simulate a car headlight viewed at a distance of $\sim 250 \mathrm{~m} .{ }^{21}$ All the images were taken at the distance foci of the specific IOL model with $5.0 \mathrm{~mm}$ pupil on the IOL under white light conditions by illumination on one side using a Fiber-Lite ${ }^{\circledR}$ DC-950 Fiber Optic Illuminator (Dolan-Jenner Industries, Boxborough, MA, USA). Test conditions, including the light intensity and the position of the IOL relative to the aperture and cornea, were the same for both IOL models. The light intensity level was adjusted until the halo structure could be clearly seen on a charge-coupled device camera.

\section{MTF measurements}

Through-focus MTF is an established method to determine the amount of contrast passed through a system at a given spatial frequency. ${ }^{22}$ The IOLs were used following ISO 11979-2 requirements and test methods in order to assess the optical properties of the multifocal IOLs using a validated Optikos MTF system according to the conditions described by Carson et al. ${ }^{5}$ MTF measurement was performed on the IOLs with spherical aberration-matching corneas to yield the best optical performance. Testing was conducted with a $3.0 \mathrm{~mm}$ lens aperture that corresponds to average photopic pupil size. Slit targets illuminated by a light source with a $550 \mathrm{~nm}$ narrow-band filter were imaged at infinity. Each target image was obtained from the IOLs, was relayed to the charge-coupled device camera, and was analyzed. MTF curves were generated from the mean vertical- and horizontal-slit values. Through-focus MTF curves at two spatial frequencies of 50 and 100 line pairs per millimeter $(\mathrm{l} / \mathrm{mm})$ were used to determine the best foci for distance, near distance, and intermediate distance. The two frequencies correspond to cycle widths of 4 and 2 minutes, respectively, conventionally equated to acuities of 20/40 and 20/20, respectively, at least for a square-wave grating. ${ }^{23}$

\section{Results \\ Badal Images}

Through-focus Badal images captured at defocus distances of infinity (0.0 D), $80 \mathrm{~cm}(1.25 \mathrm{D}), 60 \mathrm{~cm}(1.67 \mathrm{D})$, and $40 \mathrm{~cm}$ $(2.50 \mathrm{D})$ are shown in Figure 1A. The trifocal IOL provided equivalent distance and near performance compared with the multifocal IOL, with a photopic pupil size of $3.0 \mathrm{~mm}$. The intermediate visual performance was improved in the trifocal over the multifocal IOL, with approximately three lines of improvement at 60 and $80 \mathrm{~cm}$ defocus distances. The best PanOptix intermediate focus distance was $60 \mathrm{~cm}$, whereas ReSTOR +3.0 D lacks an intermediate focus. Figure 1B shows the $3.0 \mathrm{~mm}$ pupil Badal images taken at the best near focus of ReSTOR +3.0 D and PanOptix, which were $44 \mathrm{~cm}$ (2.25 D) and $42 \mathrm{~cm}$ (2.37 D), respectively.

Results were similar for PanOptix in Badal images taken at infinity $(0.0 \mathrm{D}), 80 \mathrm{~cm}(1.25 \mathrm{D}), 60 \mathrm{~cm}(1.67 \mathrm{D})$, and $40 \mathrm{~cm}(2.50 \mathrm{D})$ using the $4.5 \mathrm{~mm}$ pupil in Figure 2, whereas ReSTOR +3.0 D had less image quality at the 60 and $80 \mathrm{~cm}$ defocus positions.

The bench-simulated Badal images that were used to assess the resolution of ReSTOR +3.0 D and PanOptix IOLs were taken at defocus distances from $0.0 \mathrm{D}$ to $+3.5 \mathrm{D}$ using 

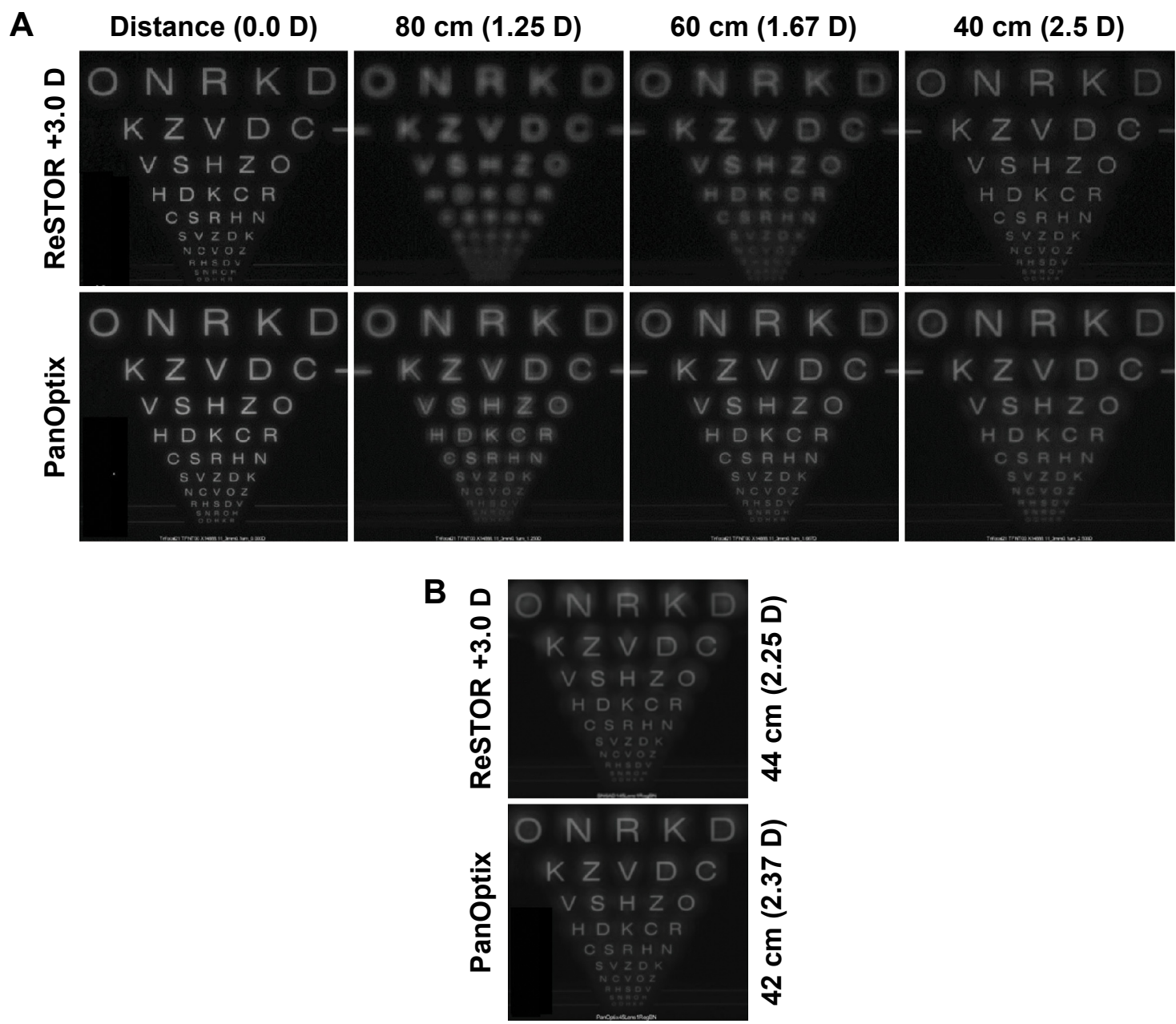

Figure I Image quality of the ReSTOR $+3.0 \mathrm{D}$ and PanOptix IOLs.

Notes: Image quality of the ReSTOR +3.0 D and PanOptix IOLs at (A) focus distances of infinity $(0.0 \mathrm{D}), 80 \mathrm{~cm}(\mathrm{I} .25 \mathrm{D}), 60 \mathrm{~cm}(\mathrm{I} .67 \mathrm{D})$ ), and $40 \mathrm{~cm}(2.5 \mathrm{D})$ with a $3.0 \mathrm{~mm}$ pupil; (B) best-near image for each IOL with a $3.0 \mathrm{~mm}$ pupil. The third line (with the text "R H S D V") and the sixth line (with the text "C S R H N") from the bottom are equivalent to visual acuities of $20 / 20$ and $20 / 40$, respectively.

Abbreviation: IOL, intraocular lens.

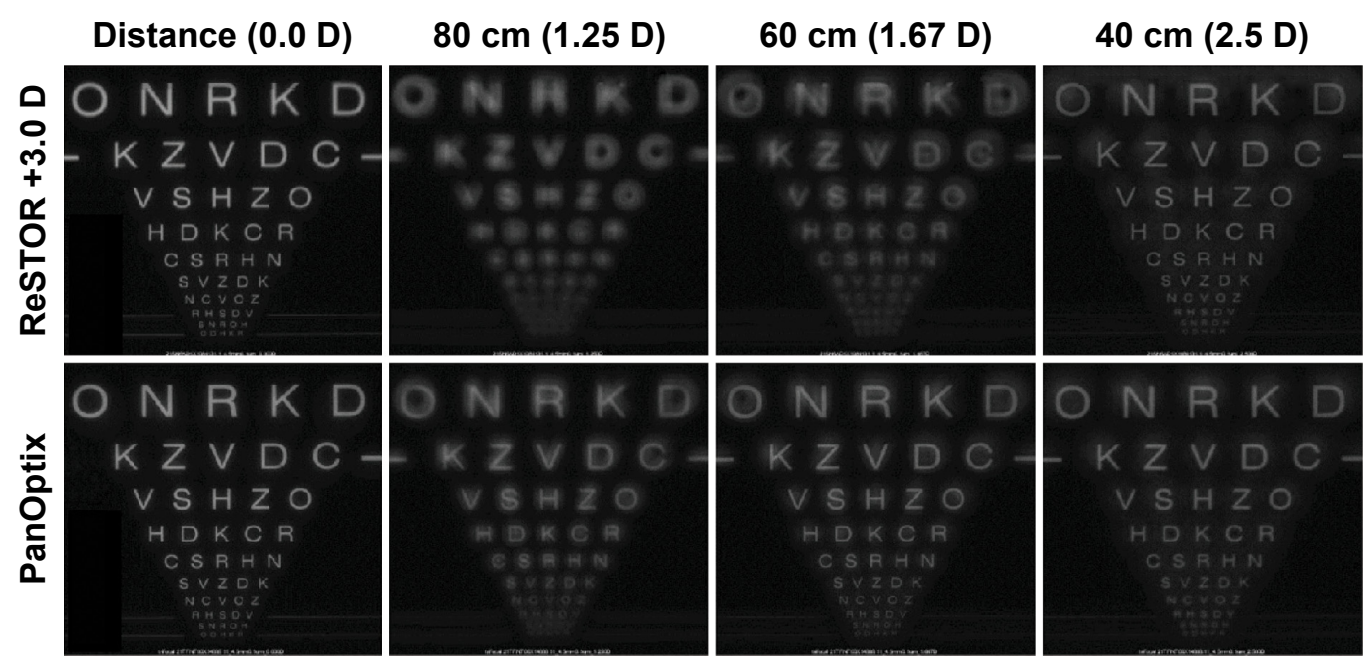

Figure 2 Image quality of the ReSTOR $+3.0 \mathrm{D}$ and PanOptix intraocular lenses at focus distances of infinity (0.0 D), $80 \mathrm{~cm}(1.25 \mathrm{D}), 60 \mathrm{~cm}(1.67 \mathrm{D})$, and $40 \mathrm{~cm}(2.5 \mathrm{D})$ with a $4.5 \mathrm{~mm}$ pupil.

Note: The third line (with the text "R H S D V") and the sixth line (with the text "C S R H N") from the bottom are equivalent to visual acuities of 20/20 and 20/40, respectively. 
the $3.0 \mathrm{~mm}$ pupil size. The following Video $\mathrm{S} 1$ shows the Badal images from ReSTOR +3.0 D (left) and PanOptix (right) over these defocus distances. The 20/40 line in PanOptix was resolvable in the $2.50 \mathrm{D}(40 \mathrm{~cm})$ to $1.25 \mathrm{D}$ $(80 \mathrm{~cm})$ images.

\section{Headlight images}

Representative simulated headlight images for the study lenses taken at the distance focus of the lenses using a $5.0 \mathrm{~mm}$ pupil are illustrated in Figure 3. The halos surrounding the headlight target diminished at a shorter distance from the central spot with the multifocal IOL compared with the trifocal IOL. Visually, halos were more distinct with PanOptix. The difference in halos can be explained by the difference in apodization between the lenses. In ReSTOR $+3.0 \mathrm{D}$, apodization helps to direct most of the light energy ( $~ 85 \%$ by design) to distance focus in large pupil diameters. On the other hand, the nonapodized PanOptix design consistently splits the light energy to the three foci (distance, intermediate, and near) independent of the pupil diameter.

\section{MTF measurements}

MTF measurements were taken at the designated foci of the two lens models with a $3.0 \mathrm{~mm}$ aperture and at spatial frequencies of 100 (Figure 4A) and $50 \mathrm{lp} / \mathrm{mm}$ (Figure 4B). Distance-focus and near-focus values were greater for ReSTOR +3.0 D than for PanOptix, but PanOptix had considerably higher intermediate MTF values.

At 100 and $50 \mathrm{lp} / \mathrm{mm}$, the ReSTOR +3.0 D IOLs had distance MTF values of $35.2 \%$ and $47.6 \%$, respectively, and the trifocal IOLs had distance MTF values of 30.9\% and $40.2 \%$, respectively. Near-focus MTF values at 100 and $50 \mathrm{lp} / \mathrm{mm}$ were $17.5 \%$ and $22.8 \%$, respectively, for ReSTOR +3.0 D and $15.3 \%$ and $18.1 \%$, respectively, for PanOptix. The intermediate-focus MTF values for PanOptix

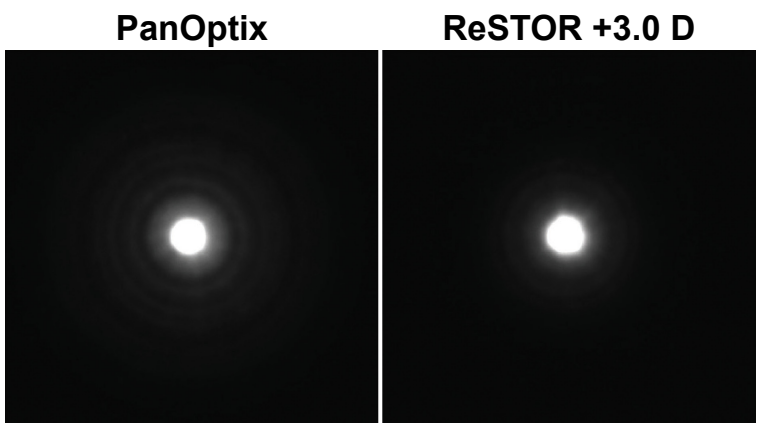

Figure 3 Simulated headlight images through the PanOptix and ReSTOR $+3.0 \mathrm{D}$ intraocular lenses. were higher than those for ReSTOR +3.0 D, as expected with the design of the trifocal IOL. Intermediate-focus MTF at 100 and $50 \mathrm{lp} / \mathrm{mm}$ were $2.9 \%$ and $4.4 \%$, respectively, for ReSTOR +3.0 D and $13.3 \%$ and $15.3 \%$, respectively, for PanOptix.

The through-focus MTF curves at spatial frequencies of 100 and $50 \mathrm{lp} / \mathrm{mm}$ using a $3.0 \mathrm{~mm}$ pupil are shown in Figure 5. The distance-focus MTF peak was greater for the multifocal IOL than the trifocal IOL. ReSTOR +3.0 D had a slightly greater near-focus MTF peak than PanOptix; the intermediate-focus peak was located at $60 \mathrm{~cm}$, and ReSTOR +3.0 D did not possess an intermediatefocus peak.

\section{Discussion}

In this study, the new PanOptix trifocal IOL design was evaluated with standard bench measurements such as through-focus Badal images for resolution, through-focus MTF curves for image quality, and headlight images for photic phenomena (halo propensity), all compared with its multifocal counterpart, ReSTOR +3.0 D. The results showed that the PanOptix IOL had improved performance at an intermediate distance range of $60-80 \mathrm{~cm}$ and showed a greater than three lines of improvement in resolution at 60,70 , and $80 \mathrm{~cm}$ compared with the ReSTOR +3.0 D IOL. Laboratory testing also showed that distance and near resolution for the trifocal IOL is likely to be comparable to ReSTOR +3.0 D for photopic pupil $(3.0 \mathrm{~mm})$. The bench simulation that was used to measure image contrast showed equivalent distance and near performance for PanOptix and ReSTOR +3.0 D IOLs, but PanOptix fared much better in intermediate vision.

Monofocal IOLs have traditionally higher contrast sensitivity than their multifocal counterparts because the light from the out-of-focus image reduces the sharpness of the in-focus image in multifocal designs. ${ }^{23}$ However, monofocal lenses are not designed to provide spectacle-free vision in situations outside of distance vision, creating a challenge for patients who need good intermediate vision (eg, computer work) and near vision (eg, reading). Diffractive multifocal IOLs have compensated for this by decreasing near add powers, ${ }^{24}$ as in the case of the ReSTOR +3.0 D, which has a decreased near add power compared with its predecessor, the ReSTOR +4.0 D. However, in this study, PanOptix was shown to produce clearer images from 60 to $80 \mathrm{~cm}$ than even the ReSTOR +3.0 D, potentially overcoming the ongoing intermediate vision and contrast sensitivity issues associated with other bifocal lenses. ${ }^{5}$ 
A

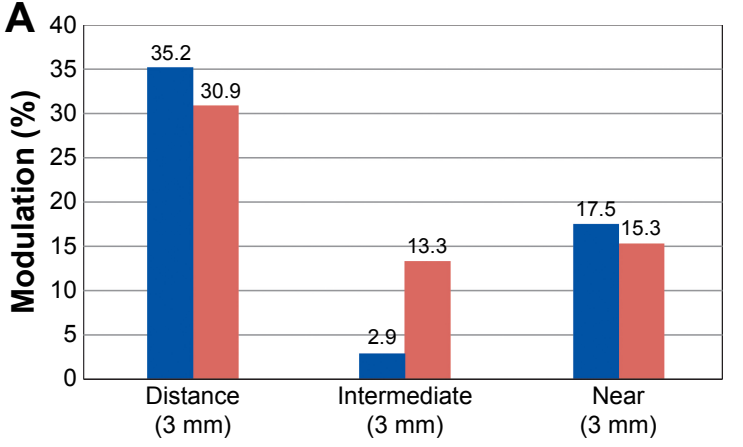

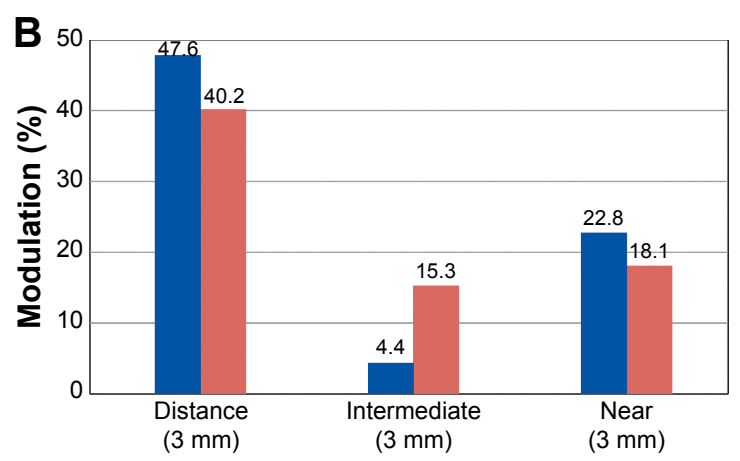

- ReSTOR +3.0 D a PanOptix

Figure 4 Modulation transfer function values of the ReSTOR $+3.0 \mathrm{D}$ and PanOptix intraocular lenses measured with a $3.0 \mathrm{~mm}$ pupil at $(\mathbf{A}) \mathrm{I00}$ and $(\mathbf{B}) 50 \mathrm{Ip} / \mathrm{mm}$ (sample size, $n=10$ ).

Abbreviation: $\mathrm{lp} / \mathrm{mm}$, line pairs per millimeter.

The higher energy usage of PanOptix allowed the IOL to provide equivalent simulated distance vision to ReSTOR +3.0 D in this study. De Vries et $\mathrm{al}^{25}$ and Alfonso et $\mathrm{al}^{26}$ found that the reduced near add power of the ReSTOR +3.0 D, compared with the ReSTOR +4.0 D or other multifocal IOLs, produced better intermediate vision, but Gatinel and Houbrechts ${ }^{11}$ maintained that true intermediate VA can only be achieved by adding a third focal point. Additionally, the intermediate and near performances of PanOptix are independent of pupil size.

The through-focus MTF curves confirmed a distance and near focus for each lens, but the curve for PanOptix also had an intermediate focus at $60 \mathrm{~cm}$. Other studies have found ReSTOR +3.0 D to have higher MTF values at near and distance focal points compared with other commercialized trifocal lenses. ${ }^{5}$ Of interest, the $60 \mathrm{~cm}$ intermediate focal point achieved by the PanOptix lens, as indicated by its MTF peak, was within the preferred viewing distance range, $45.7-61.0 \mathrm{~cm}$, for computer terminals. ${ }^{27-29}$

In addition, ReSTOR +3.0 D demonstrated slightly lowered haloing effects compared with PanOptix. The slight differences in haloing effects between the two lenses can be

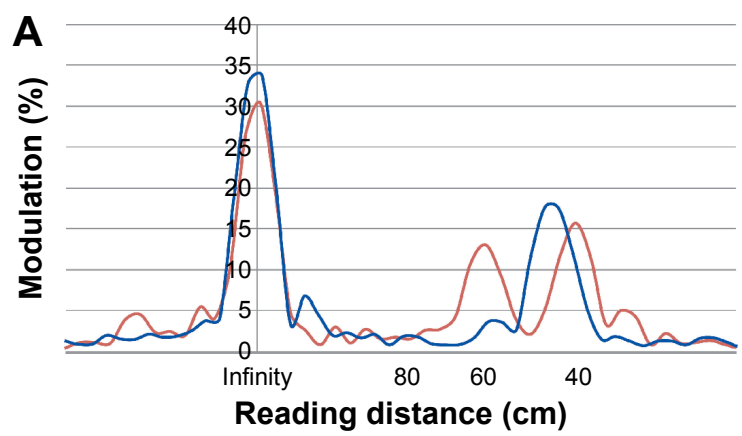

Figure 5 Through-focus modulation transfer function values of the ReSTOR +3.0 D and PanOptix intraocular lenses measured with a 3.0 mm pupil at (A) I00 and (B) $50 \mathrm{lp} / \mathrm{mm}$.

Abbreviation: Ip/mm, line pairs per millimeter.

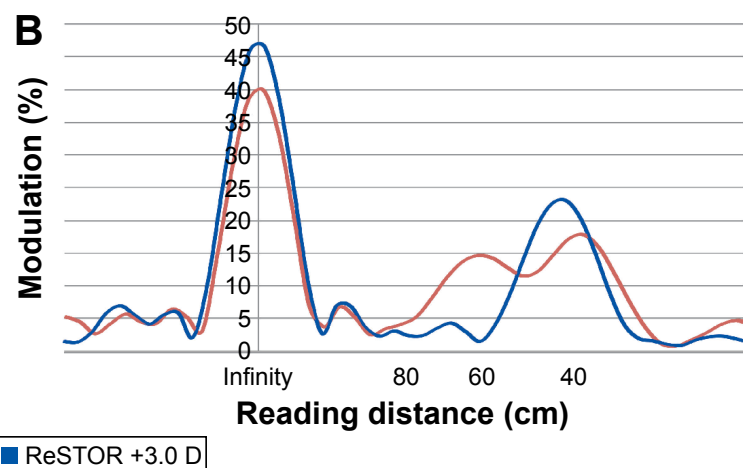

accounted for by the central apodized diffractive zone of the multifocal IOL that ends at $3.6 \mathrm{~mm}$ diameter with a refractive outer zone. ${ }^{30}$ This allows the IOL to be more strongly distancedominant with larger pupil sizes. In the nonapodized PanOptix lens, the addition of a third focus, by itself may increase halos. In large pupils, most of the light energy of ReSTOR +3.0 D ( $~ 85 \%$ by design) goes to distance focus, which may account for the variability between the two designs. It is not known whether this difference in halos between the study lenses is expected to be clinically significant, and future studies may be necessary to understand the clinical significance.

Other commercially available trifocal IOLs provide intermediate add powers at about $80 \mathrm{~cm} \cdot{ }^{17,31-34}$ However, this study showed that PanOptix provides an intermediate add power of about $60 \mathrm{~cm}$ in a unilateral bench test, which was intended to achieve the most suitable and comfortable intermediate distance for most patients. ${ }^{27-29}$

This study is limited by its laboratory nature; extrapolating the results into clinical practice may not be straightforward, and the findings cannot guarantee that the lenses will perform the same in vivo. Additionally, the study design was observational, limiting statistical analyses.

- PanOptix $\quad$ ReSTOR +3.0 D 


\section{Conclusion}

The design of PanOptix allows for the creation of three distinct foci. This novel, presbyopia-correcting lens is equivalent to ReSTOR +3.0 D in photopic near and distance performance but provides a substantial range of intermediate foci with an optimal intermediate focus at $60 \mathrm{~cm}$. Although additional clinical studies are necessary, these bench analyses have shown that PanOptix may be a viable choice for patients who require optimal vision across all distances and minimal use of spectacle correction.

\section{Acknowledgments}

This study was funded by Alcon Research, Ltd. (Fort Worth, TX, USA). The authors thank Aldo Martinez, PhD, for his thorough review and contributions to manuscript preparation. Medical writing assistance was provided by Michelle Dalton and BelMed Professional Resources and was funded by Alcon.

\section{Disclosure}

All the authors are employees of Alcon Research, Ltd. The authors report no conflicts of interest in this work.

\section{References}

1. Calladine D, Evans JR, Shah S, Leyland M. Multifocal versus monofocal intraocular lenses after cataract extraction. Cochrane Database Syst Rev. 2012;9:CD003169.

2. Lundstrom M, Barry P, Henry Y, et al. Evidence-based guidelines for cataract surgery: guidelines based on data in the European Registry of Quality Outcomes for Cataract and Refractive Surgery database. J Cataract Refract Surg. 2012;38(6):1086-1093.

3. Tan N, Zheng D, Ye J. Comparison of visual performance after implantation of 3 types of intraocular lenses: accommodative, multifocal, and monofocal. Eur J Ophthalmol. 2014;24(5):693-698.

4. Luo BP, Brown GC, Luo SC, Brown MM. The quality of life associated with presbyopia. Am J Ophthalmol. 2008;145(4):618-622.

5. Carson D, Hill WE, Hong X, Karakelle M. Optical bench performance of

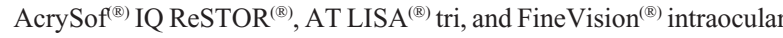
lenses. Clin Ophthalmol. 2014;8:2105-2113.

6. Gatinel D, Pagnoulle C, Houbrechts Y, Gobin L. Design and qualification of a diffractive trifocal optical profile for intraocular lenses. J Cataract Refract Surg. 2011;37(11):2060-2067.

7. Javitt J, Brauweiler HP, Jacobi KW, et al. Cataract extraction with multifocal intraocular lens implantation: clinical, functional, and quality-of-life outcomes. Multicenter clinical trial in Germany and Austria. J Cataract Refract Surg. 2000;26(9):1356-1366.

8. Mesci C, Erbil H, Ozdoker L, et al. Visual acuity and contrast sensitivity function after accommodative and multifocal intraocular lens implantation. Eur J Ophthalmol. 2010;20(1):90-100.

9. Montes-Mico R, Lopez-Gil N, Perez-Vives C, et al. In vitro optical performance of nonrotational symmetric and refractive-diffractive aspheric multifocal intraocular lenses: impact of tilt and decentration. J Cataract Refract Surg. 2012;38(9):1657-1663.

10. Ruiz-Alcocer J, Madrid-Costa D, Garcia-Lazaro S, et al. Optical performance of two new trifocal intraocular lenses: through-focus modulation transfer function and influence of pupil size. Clin Experiment Ophthalmol. 2014;42(3):271-276.

11. Gatinel D, Houbrechts Y. Comparison of bifocal and trifocal diffractive and refractive intraocular lenses using an optical bench. J Cataract Refract Surg. 2013;39(7):1093-1099.
12. de Vries NE, Webers CA, Touwslager WR, et al. Dissatisfaction after implantation of multifocal intraocular lenses. J Cataract Refract Surg. 2011;37(5):859-865.

13. Lang A, Portney V. Interpreting multifocal intraocular lens modulation transfer functions. J Cataract Refract Surg. 1993;19(4):505-512.

14. Weeber HA, Meijer ST, Piers PA. Extending the range of vision using diffractive intraocular lens technology. J Cataract Refract Surg. 2015; 41(12):2746-2754.

15. AcrySof [product information]. Fort Worth, TX: Alcon Laboratories, Inc.; 2015

16. Cochener B, Vryghem J, Rozot P, et al. Clinical outcomes with a trifocal intraocular lens: a multicenter study. J Refract Surg. 2014;30(11): $762-768$.

17. Law EM, Aggarwal RK, Kasaby H. Clinical outcomes with a new trifocal intraocular lens. Eur J Ophthalmol. 2014;24(4):501-508.

18. Alfonso JF, Fernandez-Vega L, Blazquez JI, Montes-Mico R. Visual function comparison of 2 aspheric multifocal intraocular lenses. $J$ Cataract Refract Surg. 2012;38(2):242-248.

19. Hong $X$, Zhang X. Optimizing distance image quality of an aspheric multifocal intraocular lens using a comprehensive statistical design approach. Opt Express. 2008;16(25):20920-20934.

20. He J, Carson D, Xu Z. Laboratory comparison of a novel presbyopia correcting IOL with two multifocal IOL models. European Society of Cataract and Refractive Surgeons. Barcelona, Spain; 2015.

21. Pieh S, Lackner B, Hanselmayer G, et al. Halo size under distance and near conditions in refractive multifocal intraocular lenses. Br J Ophthalmol. 2001;85(7):816-821.

22. Madrid-Costa D, Ruiz-Alcocer J, Ferrer-Blasco T, et al. Optical quality differences between three multifocal intraocular lenses: bifocal low add, bifocal moderate add, and trifocal. J Refract Surg. 2013;29(11): 749-754.

23. Bennett AG, Rabbetts RB. Bennett \& Rabbetts' Clinical Visual Optics. 3rd ed. Oxford and Boston, MA: Butterworth-Heinemann; 1998:48.

24. de Vries NE, Nuijts RM. Multifocal intraocular lenses in cataract surgery: literature review of benefits and side effects. J Cataract Refract Surg. 2013;39(2):268-278.

25. de Vries NE, Webers CA, Montes-Mico R, et al. Long-term follow-up of a multifocal apodized diffractive intraocular lens after cataract surgery. J Cataract Refract Surg. 2008;34(9):1476-1482.

26. Alfonso JF, Fernandez-Vega L, Puchades C, Montes-Mico R. Intermediate visual function with different multifocal intraocular lens models. J Cataract Refract Surg. 2010;36(5):733-739.

27. American Optometric Association. The Effects of Computer Use on Eye Health and Vision. St. Louis, MO: American Optometric Association; 1997.

28. Charness N, Dijkstra K, Jastrzembski T, et al. Monitor Viewing Distance for Younger and Older Workers: Proceedings of the Human Factors and Ergonomics Society 52nd Annual Meeting. 2008;52(19): 1614-1617.

29. U.S. Department of Labor, Occupational Safety and Health Administration. Working Safely with Video Display Terminals. OSHA Publication 3092; revised 1997. Available from: https://www.osha.gov/ Publications/osha3092.pdf. Accessed August 4, 2015.

30. Fisher BL. Presbyopia-correcting intraocular lenses in cataract surgery: literature review of the benefits and side effects. $J$ Cataract Refract Surg. 2013;39(2):268-278.

31. Carballo-Alvarez J, Vazquez-Molini JM, Sanz-Fernandez JC, et al. Visual outcomes after bilateral trifocal diffractive intraocular lens implantation. BMC Ophthalmol. 2015;15:26.

32. Casas P, Cristobal JA, Angeles del Buey M. Objective and subjective visual performance of a diffractive trifocal implant. J Emmetropia. 2014; 5:183-189.

33. Kretz FT, Breyer D, Diakonis VF, et al. Clinical outcomes after binocular implantation of a new trifocal diffractive intraocular lens. J Ophthalmol. 2015;2015:962891.

34. Vryghem JC, Heireman S. Visual performance after the implantation of a new trifocal intraocular lens. Clin Ophthalmol. 2013;7:1957-1965. 


\section{Publish your work in this journal}

Clinical Ophthalmology is an international, peer-reviewed journal covering all subspecialties within ophthalmology. Key topics include: Optometry; Visual science; Pharmacology and drug therapy in eye diseases; Basic Sciences; Primary and Secondary eye care; Patient Safety and Quality of Care Improvements. This journal is indexed on

PubMed Central and CAS, and is the official journal of The Society of Clinical Ophthalmology (SCO). The manuscript management system is completely online and includes a very quick and fair peer-review system, which is all easy to use. Visit http://www.dovepress.com/ testimonials.php to read real quotes from published authors. 